\title{
Resolution of Corneal Fibrosis After Descemet's Stripping Automated Endothelial Keratoplasty: A Case Report
}

\author{
Marta Zola • Jaeryung Kim • Myrsini Petrelli - Lydia Schmutz • \\ Kattayoon Hashemi · George Kymionis
}

Received: January 18, 2020 / Published online: March 6, 2020

(C) The Author(s) 2020

\section{ABSTRACT}

Purpose: To report the resolution of anterior corneal fibrosis after Descemet's stripping automated endothelial keratoplasty (DSAEK), in a patient with chronic corneal edema and anterior stromal scarring.

Methods: A 63-year-old woman, with a history of Fuchs endothelial dystrophy, presented with increasing discomfort and gradual visual loss in her right eye. Clinical examination revealed longstanding bullous keratopathy accompanied by marked subepithelial fibrosis (SEF). Based on the low postoperative visual potential due to glaucomatous optic neuropathy, we decided to proceed with DSAEK.

Results: During the follow-up period, SEF was found to gradually resolve. Corneal clarity was restored and an improvement in visual acuity was observed up to 12 months after surgery.

Enhanced Digital Features To view enhanced digital features for this article go to https://doi.org/10.6084/ m9.figshare.11890431.

M. Zola · J. Kim · M. Petrelli · L. Schmutz ·

K. Hashemi · G. Kymionis $(\square)$

Department of Ophthalmology, Jules-Gonin Eye

Hospital, University of Lausanne, Fondation Asile

des aveugles, Lausanne, Switzerland

e-mail: gkymionis@gmail.com

J. Kim

Department of Ophthalmology, Samsung Medical

Center, Sungkyunkwan University School of

Medicine, Seoul, Republic of Korea
Conclusion: DSAEK alone may represent an effective therapeutic option for the restoration of impaired corneal clarity in patients with long-standing corneal edema and concomitant anterior subepithelial scarring.

Keywords: Bullous keratopathy; Corneal subepithelial fibrosis; Descemet's stripping automated endothelial keratoplasty

\section{Key Summary Points}

Descemet's stripping automated endothelial keratoplasty (DSAEK) has surpassed penetrating keratoplasty (PK) as the preferred treatment method for patients with corneal endothelial dysfunction.

Nevertheless, PK remains the gold standard treatment for patients with visually significant corneal scarring.

In this report, the authors present a patient with long-standing corneal edema and extensive subepithelial fibrosis that showed restoration of corneal clarity following DSAEK alone.

DSAEK could be considered as an alternative therapeutic option in cases of advanced bullous keratopathy with anterior stromal fibrosis, especially in patients with low postoperative visual potential or a contraindication for PK. 


\section{INTRODUCTION}

Descemet's stripping automated endothelial keratoplasty (DSAEK) has replaced penetrating keratoplasty (PK) as the preferred surgical method for patients with corneal endothelial decompensation $[1,2]$. The advantages of DSAEK over traditional PK include faster visual recovery, refractive and tectonic stability, absence of suture-related complications, and lower intraoperative and late postoperative risk, in particular graft rejection [3, 4]. Despite its wide acceptance, however, DSAEK is relatively contraindicated in patients with visually significant corneal opacities or scarring, and PK remains the gold standard for the treatment of the latter.

In this report, we present a patient with longstanding corneal edema and extensive subepithelial fibrosis (SEF), who showed restoration of corneal clarity following DSAEK alone.

Procedures related to this case report were conducted ethically in accordance with the tenets of the Declaration of Helsinki. The subject gave her consent to publish this report. No identifiable patient information is shown in this manuscript.

\section{CASE REPORT}

A 63-year-old woman was referred to our clinic for corneal transplantation due to severe bullous keratopathy secondary to Fuchs endothelial dystrophy in her right eye. Her past ocular history included primary open-angle glaucoma with advanced optic neuropathy in the right eye. She reported undergoing uneventful phacoemulsification, with posterior chamber intraocular lens implantation, in the involved eye 3 years before presentation and pars plana vitrectomy for vitreous floaters 2 years earlier. Topical treatment included latanoprost $0.005 \% /$ timolol $0.5 \%$ (Xalacom $^{\circledR}$, Pfizer, USA) in the right eye.

Best-corrected visual acuity (BCVA) was "hand motion" in the right eye and 20/20 in the left eye. Intraocular pressure measured by pneumotonometry was $17 \mathrm{mmHg}$ in the right eye and $13 \mathrm{mmHg}$ in the left eye. Slit-lamp examination of the right eye revealed severe bullous keratopathy with accompanying SEF (Fig. 1a). Left eye examination revealed cornea guttata without corneal edema or stromal fibrosis. Anterior segment optical coherence tomography (AS-OCT; Spectralis, Heidelberg, Germany) depicted the corneal edema and the coexisting SEF (Fig. 1b). As the corneal edema and scarring obscured direct fundus visualization, B-scan ultrasonography was performed to exclude the presence of severe posterior segment abnormalities.

Considering the low postoperative visual potential based on the patient's glaucoma history and medical record (BCVA was 20/100 before the manifestation of bullous keratopathy), we decided to proceed with DSAEK followed by possible phototherapeutic keratectomy (PTK) for removal of the fibrosis $[5,6]$. Informed consent was obtained from the patient.

The DSAEK procedure was performed under sub-Tenon's block. After removal of the loosened central corneal epithelium with the use of a Merocel $^{\circledR}$ ophthalmic sponge (Medtronic Xomed, Inc., Jacksonville, FL, USA) in order to facilitate visualization of the anterior chamber, areas of corneal stromal fibrosis became more evident. A 3.2-mm limbal incision was performed at 12 o'clock, followed by three side ports at 3, 6, and 9 o'clock. After filling the anterior chamber with air, stripping of the recipient's Descemet's membrane (DM) was performed using a reverse Sinskey hook. A precut corneal graft with thickness of $71 \mu \mathrm{m}$ and endothelial cell density of 2300 cells $/ \mathrm{mm}^{2}$ was used. Following removal of the anterior cap, a 7.0-mm graft was placed onto a Busin glide (Moria SA, Mömbris, Germany) and pulled through the corneal incision into the anterior chamber using a fine intraocular forceps (Busin forceps, Moria SA). The incision wound was sutured using 10-0 nylon. At the end, the anterior chamber was filled completely with $100 \%$ air.

The postoperative period was uneventful. The graft remained clear and attached, and steroids were used in tapering doses. Complete resolution of the corneal edema was observed at 2 weeks following the surgery. Interestingly, the 

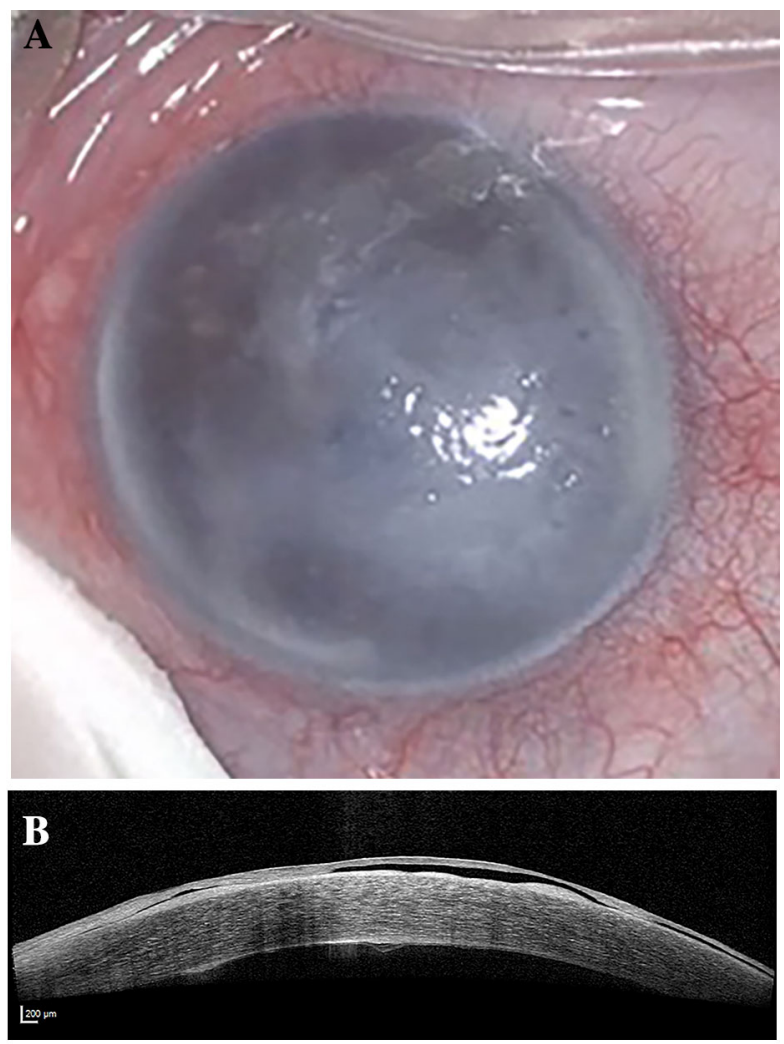

Fig. 1 Preoperative slit-lamp photo (a) and anterior segment optical coherence tomography (AS-OCT) (b) of the patient's right eye showing advanced bullous keratopathy accompanied by subepithelial fibrosis (SEF)

anterior stroma gradually cleared, and the preexisting fibrosis resolved 6 months postoperatively (Fig. 2a), as demonstrated by comparing preoperative and postoperative AS-OCT images (Figs. $1 \mathrm{~b}$ and 2b). Furthermore, BCVA slowly ameliorated and stabilized at 20/100 at 12 months.

\section{DISCUSSION}

Endothelial keratoplasty (EK) has replaced PK as the treatment of choice for corneal edema arising from corneal endothelial disorders such as Fuchs endothelial dystrophy and pseudophakic bullous keratopathy, with DSAEK and Descemet's membrane endothelial keratoplasty (DMEK) representing the most commonly performed EK techniques. In DSAEK, the host DM and endothelium are replaced by donor posterior stroma, DM, and endothelium, whereas in DMEK the graft consists only of donor DM and endothelium. Nevertheless, the presence of marked anterior corneal scarring may limit the final visual outcome; hence, PK has traditionally been the surgical treatment of choice in the presence of corneal fibrosis. Alternative therapeutic options have been reported in the past, including a two-step procedure, such as DSAEK combined with transepithelial PTK and adjunctive mitomycin $\mathrm{C}[5,6]$.

Using in vivo laser confocal microscopy, Morishige et al. found that preoperative SEF observed in bullous keratopathy was usually detected in patients with long-standing corneal stromal edema of more than 12 months [7]. In addition, in approximately one-third of the patients who underwent DSAEK, persistent SEF was still detected 1 year postoperatively. Taking into consideration this observation, they hypothesized that the duration of preoperative stromal edema is a key determining factor for the resolution of the SEF and the final DSAEK outcome [7]. Nevertheless, in our case, we 


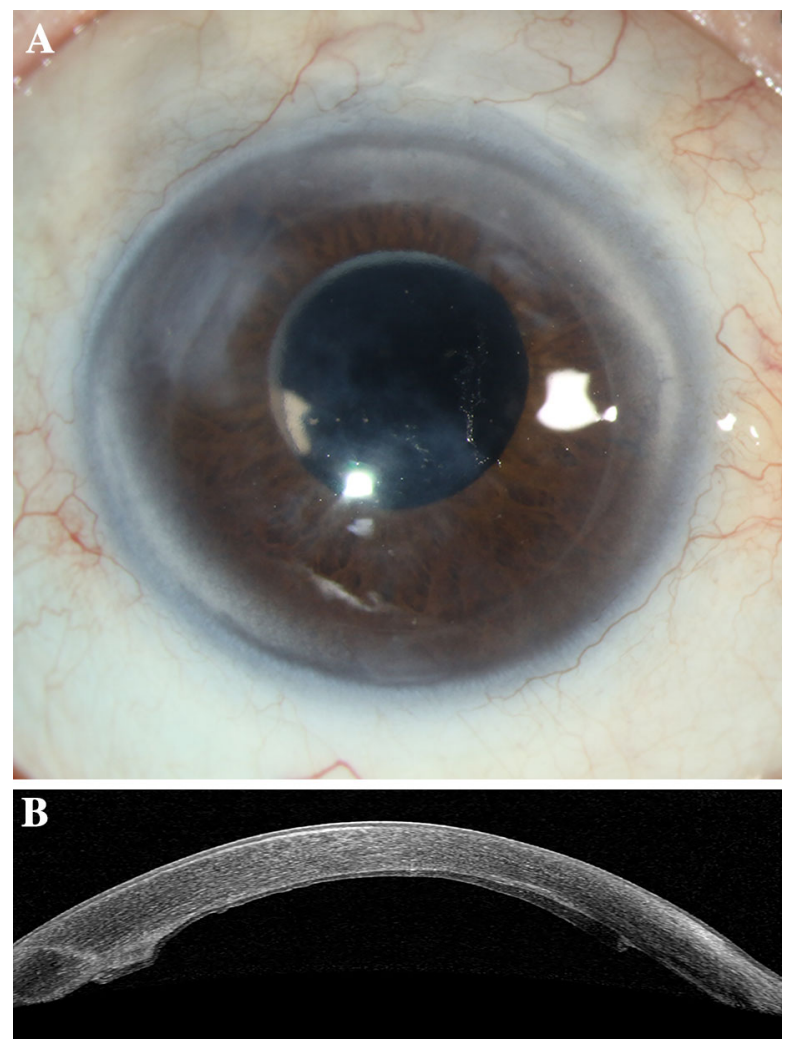

Fig. 2 Slit-lamp photo (a) and anterior segment optical coherence tomography (AS-OCT) (b) 6 months after DSAEK demonstrating complete resolution of the anterior stromal fibrosis and the return of corneal transparency

observed complete resolution of the severe anterior corneal scarring 12 months following surgery, despite the long-standing bullous keratopathy.

The development and persistence of mature myofibroblasts in the corneal stroma are key steps in the development of stromal fibrosis [8]. At the site of epithelial basement membrane (EBM) injury, transforming growth factor (TGF)J3 and platelet-derived growth factor released from epithelial cells penetrate the stroma and initiate the development of myofibroblasts [8], which contribute to the abnormal distribution of extracellular matrix (ECM) [9, 10]. Similarly to EBM injury, it has been reported that corneal myofibroblasts and stromal fibrosis persisted when the Descemet membrane was damaged [11]. In addition, activation of TGF-J3 signaling in Fuchs endothelial dystrophy mediates excessive accumulation of ECM proteins [12]. In long-standing corneal edema with epithelial bullae due to endothelial dysfunction, both the EBM and Descemet membrane are defective. Thus, corneal basement membranes (EBM and Descemet membrane) are the modulators of the corneal fibrosis response [8]. Endothelial keratoplasty restores adequate hydration of the stroma by restoring Descemet membrane function.

In this regard, a possible mechanism explaining regression of SEF in our case could be that the resolution of the stromal edema observed following DSAEK induced the clearance of myofibroblasts, the repopulation of keratocytes and reabsorption of the abnormal ECM components. We also performed epithelial removal during our patient's procedure. Epithelial debridement has been shown to induce senescence of stromal fibroblasts and may thus be involved in the resolution of corneal fibrosis [13]. In addition, the use of topical steroids during the postoperative period may have played a key role, as its use has been shown to reduce scar tissue formation [14].

Corneal fibrosis may undergo spontaneous resolution over months to years with a return of partial to full corneal transparency $[8,15]$. Thus, we claim that PK should not be systematically proposed and DSAEK could be considered as a therapeutic option in patients with endothelial dysfunction and stromal fibrosis, especially in cases of patients with low visual potential or who cannot undergo PK, such as patients under anticoagulant therapy.

\section{ACKNOWLEDGEMENTS}

Funding. The authors declare that no funding or sponsorship was received for this case report or publication of this article.

\section{Medical Writing, Editorial, and Other} Assistance. Editorial assistance for this study was provided by Aleksandra Petrovic, MD, of the Department of Ophthalmology, University of Lausanne, Jules-Gonin Eye Hospital, Fondation Asile des aveugles, Lausanne, Switzerland. 
Authorship. All named authors meet the International Committee of Medical Journal Editors (ICMJE) criteria for authorship for this article, take responsibility for the integrity of the work as a whole, and have given their approval for this version to be published.

Disclosures. Marta Zola, Jaeryung Kim, Myrsini Petrelli, Lydia Schmutz, Kattayoon Hashemi and George D. Kymionis have no conflicts of interest to declare.

Compliance with Ethics Guidelines. The procedures in this case report were conducted ethically in accordance with the tenets of the Declaration of Helsinki. The subject gave her consent to publish this report. No identifiable patient information is shown in this manuscript.

Data Availability. Data sharing is not applicable to this article, as no datasets were generated or analyzed during the current study.

Open Access. This article is licensed under a Creative Commons Attribution-NonCommercial 4.0 International License, which permits any non-commercial use, sharing, adaptation, distribution and reproduction in any medium or format, as long as you give appropriate credit to the original author(s) and the source, provide a link to the Creative Commons licence, and indicate if changes were made. The images or other third party material in this article are included in the article's Creative Commons licence, unless indicated otherwise in a credit line to the material. If material is not included in the article's Creative Commons licence and your intended use is not permitted by statutory regulation or exceeds the permitted use, you will need to obtain permission directly from the copyright holder. To view a copy of this licence, visit http://creativecommons.org/licenses/by$\mathrm{nc} / 4.0 /$.

\section{REFERENCES}

1. Veldman PB, Terry MA, Straiko MD. Evolving indications for Descemet's stripping automated endothelial keratoplasty. Curr Opin Ophthalmol. 2014;25:306-11.

2. Price MO, Price FW Jr. Endothelial keratoplasty-a review. Clin Exp Ophthalmol. 2010;38:128-40.

3. Lee WB, Jacobs DS, Musch DC, et al. Descemet's stripping endothelial keratoplasty: safety and outcomes: a report by the American Academy of Ophthalmology. Ophthalmology. 2009;116: 1818-30.

4. Chen ES, Terry MA, Shamie N, et al. Descemetstripping automated endothelial keratoplasty: insertion using a novel 40/60 underfold technique for preservation of donor endothelium. Cornea. 2008;27:941-3.

5. Awdeh RM, Abbey AM, Vroman DT, et al. Phototherapeutic keratectomy for the treatment of subepithelial fibrosis and anterior corneal scarring after Descemet stripping automated endothelial keratoplasty. Cornea. 2012;31:761-3.

6. Kymionis G, Oikonomakis $\mathrm{K}$, Petrelli $\mathrm{M}$, et al. Treatment of anterior corneal scarring, following DSAEK graft failure, with combined graft exchange and phototherapeutic keratectomy. Eye Vis (Lond). 2017;4:12.

7. Morishige N, Yamada N, Morita Y, et al. Persistence of structural changes at the anterior cornea in bullous keratopathy patients after endothelial keratoplasty. PLoS One. 2013;8:e74279.

8. Medeiros CS, Marino GK, Santhiago MR, et al. The corneal basement membranes and stromal fibrosis. Invest Ophthalmol Vis Sci. 2018;59:4044-53.

9. Morishige N, Yamada N, Teranishi S, et al. Detection of subepithelial fibrosis associated with corneal stromal edema by second harmonic generation imaging microscopy. Invest Ophthalmol Vis Sci. 2009;50:3145-50.

10. Ljubimov AV, Burgeson RE, Butkowski RJ, et al. Extracellular matrix alterations in human corneas with bullous keratopathy. Invest Ophthalmol Vis Sci. 1996;37:997-1007.

11. Marino GK, Santhiago MR, Santhanam A, et al. Epithelial basement membrane injury and regeneration modulates corneal fibrosis after pseudomonas corneal ulcers in rabbits. Exp Eye Res. 2017;161:101-5. 
12. Okumura N, Minamiyama R, Ho LT, et al. Involvement of ZEB1 and Snail1 in excessive production of extracellular matrix in Fuchs endothelial corneal dystrophy. Lab Invest. 2015;95:1291-304.

13. Wang X, Qu M, Li J, et al. Induction of fibroblast senescence during mouse corneal wound healing. Invest Ophthalmol Vis Sci. 2019;60:3669-79.
14. Wilson SL, El Haj AJ, Yang Y. Control of scar tissue formation in the cornea: strategies in clinical and corneal tissue engineering. J Funct Biomater. 2012;3:642-87.

15. Torricelli AA, Wilson SE. Cellular and extracellular matrix modulation of corneal stromal opacity. Exp Eye Res. 2014;129:151-60. 